\title{
Welfare Effects of Compulsory Licensing
}

\author{
Jacob Seifert \\ Submitted 9 December 2014 \\ Submitted in Revised Form 8 May, 6 August, 2 October \& 4 October 2015
}

The final publication is available at Springer via http://dx.doi.org/10.1007/s11149-015-9288-9

\begin{abstract}
This paper derives necessary and sufficient conditions for compulsory licensing to increase consumer surplus and total welfare, taking into account both static (technology transfer) and dynamic (innovation) effects. When the risk-free rate is low, compulsory licensing is shown unambiguously to increase consumer surplus. Compulsory licensing has an ambiguous effect on total welfare, but is more likely to increase total welfare in industries that are naturally less competitive. Finally, compulsory licensing is shown to be an effective policy to protect competition per se. The paper also demonstrates the robustness of these results to alternative settings of R\&D competition and discusses their significance for the debate on compulsory licensing in the context of standard-setting organisations and pharmaceutical trade.
\end{abstract}

Keywords competition policy, compulsory licensing, innovation, welfare

JEL Classification D43, L13, L41, L51, O31

\section{Introduction}

It is well known that the unregulated exploitation by firms of their intellectual property (IP) rights can limit competition. ${ }^{1}$ This paper examines a particular type of anti-competitive conduct relating to a firm's use of its IP: the unilateral refusal by a dominant firm to license. Particularly in Europe, such a refusal to license is seen as a potential abuse of a dominant position under competition law. Competition bodies may therefore impose a compulsory licence - a legal obligation to share IP in exchange for fair, reasonable and non-discriminatory (FRAND) compensation ${ }^{2}-$ on a firm that does not license its innovation voluntarily, in order to promote competition in the market. Of course, the argument against compulsory licensing is that, by undermining the IP protection of innovating firms, it reduces firms' incentives to innovate (see, e.g., Feldman 2009). The impact of compulsory licensing on welfare is, therefore, ambiguous, since it promotes competition only at the expense of reduced innovation incentives. The aim of this paper is to analyse these conflicting effects, and to derive necessary and sufficient conditions for compulsory licensing to improve welfare.

\author{
J. Seifert \\ University of Manchester, School of Social Sciences (Economics), Manchester M13 9PL, UK \\ Tel.: +44 (0)161306 8022 \\ e-mail: jacob.seifert@manchester.ac.uk
}

${ }^{1}$ This might occur through horizontal or cross-licensing agreements, patent pools or patent settlements that facilitate
product market collusion, through vertical licensing deals that facilitate resale price maintenance arrangements, as
well as through tying of patented products and refusals to license. See Pate (2003) and Katsoulacos (2009).
${ }^{2}$ This was the remuneration principle implemented in the European Microsoft case: "The requirement for the terms
imposed by Microsoft to be reasonable and non-discriminatory applies in particular to any remuneration that
Microsoft might charge for supply. For example, such remuneration should not reflect the strategic value stemming
from Microsoft's market power in the PC operating system market or in the work group server operating system
market." (European Commission 2007 , 131 . Emphasis added.) In this paper, we will follow the vast majority of the
literature (e.g. Schmalensee 2009; Carlton and Shampine 2013) by not differentiating reasonable and non-
discriminatory licensing terms from those that are fair, reasonable and non-discriminatory. Instead, we rely on the
most commonly-used acronym, FRAND. We discuss the issue of FRAND licensing in more detail as part of the
regulatory implications covered in Section 6 . 
The appropriate legal treatment of refusals to license IP has been a central issue in numerous highprofile competition cases. In the US, the courts have consistently upheld the rights of IP holders and have considered the unilateral refusal by a dominant firm to license a competition violation only if it is accompanied by a secondary harmful action, such as tying or exclusive dealing, or if it violates agreements made as part of membership of a standard setting organisation (SSO) (Coco 2008). In Xerox, the Court of Appeals for the Federal Circuit effectively granted the innovator immunity from Section 2 of the Sherman Act for the refusal to license, deeming such a refusal to lie within the scope of patent rights. ${ }^{3}$ Similarly, the 2007 joint report by the US Department of Justice (DOJ) and Federal Trade Commission (FTC) on Antitrust Enforcement and IP Rights states that "[a]ntitrust liability for mere unilateral, unconditional refusals to license patents will not play a meaningful part in the interface between patent rights and antitrust protections." (DOJ-FTC 2007, p. 6) By contrast, the European competition bodies (collectively, the European Commission, the Court of First Instance (CFI) and the European Court of Justice (ECJ)) do consider the refusal to license IP a potential violation of competition law and have imposed and upheld compulsory licenses in several landmark cases, most notably in Microsoft, but also in IMS Health and Magill. ${ }^{4}$

It is helpful to consider this divergence in approaches between the US and Europe in terms of the underlying legal standard (or decision rule) by which refusals to license IP are judged, as this is an area in which important analytical work on compulsory licensing exists (Katsoulacos 2009). Legal standards for competition policy may be broadly split between per se rules and discriminating rules. Under a per se rule, an entire class of actions is allowed or disallowed, without attempting to identify sub-classes of actions that might merit exception from the rule. This implies that per se rules are associated only with decision errors of type I (false convictions) or type II (false acquittals), but never both, depending on whether the rule is one of per se illegality or per se legality, respectively. Under a discriminating rule, an investigation is conducted and a decision is arrived at, based on explicit criteria for deeming actions to be pro- or anti-competitive (Katsoulacos and Ulph 2009). In consequence, discriminating rules are generally associated with decision errors of both types. It is therefore natural to distinguish further between discriminating rules according to whether they are relatively more focused on preventing false convictions or on preventing false acquittals.

Katsoulacos (2009) argues that the US approach in Xerox is equivalent to per se legality, ${ }^{5}$ while the Commission's legal standard in Microsoft is an example of a low-false-acquittals discriminating rule. The legal standard in the Magill and IMS Health cases, meanwhile, is argued to be a low-false-convictions discriminating rule. ${ }^{6}$ In a welfare framework, the desirability of these competing legal standards is related to the underlying or average degree of harm associated with refusals to license IP. This average harm is, in turn, reflected in the 'presumption of legality', formally defined as the ratio of the expected benefit from refusals to license IP that are benign (that is, for which welfare falls if compulsory licensing is imposed) to the expected harm from refusals to license that are truly harmful (that is, for which compulsory licensing would improve welfare). The key insight is that the per se legality standard adopted in the US Xerox case is welfare-preferred to the discriminating rules (be they of the low-false-acquittals or low-false-convictions type) adopted by the Commission only if the presumption of legality is high. However, the extent to which refusals to license IP should actually be viewed as presumptively legal is discussed only informally.

This paper therefore also builds on Katsoulacos (2009), by investigating more carefully the presumption of legality that should apply to refusals to license IP. In particular, we take explicit account

\footnotetext{
${ }^{3}$ CSU, LLC v. Xerox Corp., 203 F.3d 1322 (Fed. Cir. 2000). The US Patent Act, Section 271(d) states that "[n]o patent owner otherwise entitled to relief for infringement or contributory infringement of a patent shall be denied relief or deemed guilty of misuse or illegal extension of the patent right by reason of his having done one or more of the following: ... (4) refused to license or use any rights to the patent."

${ }^{4}$ Microsoft v. Commission, Case T201/04 (2007); IMS Health and NDC Health v. Commission, Case C418/01 (2004), ECR I-5039; and Magill ITP, BBC and RTE v. Commission, Cases C241/91 and C242/91 P (1995), ECR I-743.

${ }^{5}$ It should be emphasised that, even in the US, the application of the per se legality legal standard has not been uniform. In Kodak, a "rebuttable presumption" or modified per se legality standard was employed. See Katsoulacos (2009) and Coco (2008) for details. Even in the US, therefore, the appropriate legal treatment of refusals to license IP is not a settled matter. Eastman Kodak Co. v. Image Technical Services Inc., 125 F.3d 1195 (9th Cir. 1997).

${ }^{6}$ The move from a low-false-convictions "exceptional circumstances" rule in IMS Health and Magill towards a lowfalse-acquittals rule in Microsoft is seen by some as going along with the Commission's move towards a more economics-based approach, and the related belief that refusals to license IP are likely to be harmful in a much wider range of circumstances than previously supposed, necessitating a more stringent approach (Katsoulacos 2009).
} 
of innovation effects and investigate when compulsory licensing improves welfare, relative to the case where a dominant firm would refuse to license its innovation voluntarily. ${ }^{7}$ Our innovation results are derived within the framework of a single innovation tournament model of R\&D competition, in which the imposition of compulsory licensing (by weakening the IP protection of innovators) always lowers innovation incentives. While several models have shown that weakening IP protection can actually increase innovation rates, ${ }^{8}$ we justify this modelling assumption as follows. The majority of competition authorities around the world, including in the US and EU, follow a consumer surplus standard. ${ }^{9}$ In that context, were innovation rates to rise in response to a compulsory licence, such a policy would represent a win-win situation for consumers. To make the trade-off between innovation and competition real, we must therefore have a reduction in R\&D incentives when compulsory licensing is imposed. While this may be achieved in more complex dynamic models, ${ }^{10}$ the simplest such model is a one-shot tournament model. ${ }^{11}$ Our contribution to the literature on the strength of IP protection and innovation incentives more broadly is that, in our framework, we explicitly balance the negative effect that compulsory licensing has on innovation incentives with its pro-competitive impact in the product market to arrive at explicit welfare results.

We derive our welfare results on the basis of both a consumer surplus and a total welfare standard, as well as in the case where the competition authority cares about protecting competition per se under a socalled foreclosure standard. We are able to show that, when the risk-free rate is low, consumer surplus is always higher when a dominant firm is forced to license via compulsory licensing, because this guarantees that the most preferred consumer outcome (that associated with technology transfer) is realised. This result therefore contradicts the view that refusals to license IP should be viewed as strongly presumptively legal, and consequently treated under a per se legality standard. ${ }^{12}$ Instead, on the basis of Katsoulacos (2009), the discriminating rules adopted by the Commission appear more reasonable. ${ }^{13}$ The effect of compulsory licensing on total welfare is more complex, but is shown to be positive whenever the underlying degree of competitiveness in the industry is sufficiently low. We also show that compulsory licensing is an effective policy to protect competition per se, since it guarantees that the incumbent cannot foreclose its less-efficient rival.

While these results are derived in a baseline model in which the incumbent is the predicted winner of the innovation race - a scenario we refer to as persistent dominance - we also demonstrate their

\footnotetext{
${ }^{7}$ The welfare effects of compulsory licensing have previously been discussed in Chen (2014), Stavropoulou and Valletti (2015) and Bond and Saggi (2012). Our results extend Chen (2014), by treating innovation as a continuous rather than a binary variable. While the latter approach gives insights into the cases where innovation either falls to zero or remains unchanged following the imposition of compulsory licensing, our approach allows us to look at the important intermediate cases where innovation rates may fall somewhat in response to compulsory licensing. Stavropoulou and Valletti (2015) and Bond and Saggi (2012) investigate the welfare effects of compulsory licensing in the specific context of North-South pharmaceutical trade, while our model is general.

${ }^{8}$ See, e.g., Segal and Whinston (2007), who emphasise the front-loading effect, according to which weaker protection for innovative entrants may increase $R \& D$, since it increases the incentives to innovate in order to replace the (more protected) incumbent. In models of sequential innovation, the neck-and-neck effect predicts that firms will invest more in $\mathrm{R} \& \mathrm{D}$ when they are closer together, so that the bunching of firms that is brought about by compulsory licensing may promote R\&D spending in subsequent stages of innovation. See Aghion et al. (2001). These effects are discussed in more detail in Vickers (2010).

${ }^{9}$ Two exceptions are Canada and New Zealand, which follow a total welfare standard.

${ }^{10}$ See, e.g., Acemoglu and Akcigit (2012). They show that a so-called trickle-down effect makes a staggering of compulsory licensing fees optimal, whereby firms that are furthest behind pay more for the licence. While this mitigates the fall in innovation rates compared to a uniform compulsory licensing policy, innovation rates do still fall relative to the full IP protection benchmark.

${ }^{11}$ This paper also relates to the literature on the impact of downstream competition on upstream innovation decisions, as in Iskhakov et al. (2013). In particular, we consider the case in which competition is promoted via the imposition of a compulsory licence, which simultaneously weakens IP protection. See Gilbert and Shapiro (1996) and Kühn and Van Reenen (2008) for more general discussion of the R\&D effects of compulsory licensing.

${ }^{12}$ Rather, this results suggests that refusals to license should be viewed as strongly presumptively illegal if consumer surplus is the relevant welfare measure.

${ }^{13}$ In terms of the wider differences between the US and European competition policy regimes, it is worth noting that in the US, antitrust claims are normally private, while in Europe they are generally public, with the Commission acting as prosecutor and judge, subject to the judicial review of the CFI and ECJ (Coco 2008). While this paper does not consider directly the optimal structure of competition law enforcement, our conclusion that the presumption of legality in refusal to license cases is very low does suggest that the degree of regulatory oversight associated with the European system more generally is, in this context, desirable.
} 
robustness to an alternative setting of action-reaction $\mathrm{R} \& \mathrm{D}$ competition, in which the less-efficient firm is predicted to overtake the incumbent by innovating successfully. ${ }^{14}$ It is important to verify that the incentives for dominant firms to refuse to license and the welfare effects of compulsory licensing carry over to the action-reaction setting, since here the dominance of the incumbent firm is, at least in the dynamic sense, weaker. ${ }^{15}$

Finally, we relate our welfare results to the debate on compulsory licensing in the context of SSOs and pharmaceutical trade. While both settings contain additional features that go beyond the framework developed in this paper, we argue that our work nevertheless serves as a useful benchmark for the study of compulsory licensing in these cases. This follows because our setting is arguably that in which the $a$ priori arguments for compulsory licensing are weakest, making our results in favour of such a policy, especially under a consumer surplus standard, particularly noteworthy.

The remainder of the paper is organised as follows. Section 2 outlines the model. Section 3 discusses the innovation effects of compulsory licensing in the benchmark, persistent dominance case, while Section 4 derives the main welfare results. Section 5 discusses the robustness of our results to actionreaction $R \& D$ competition, before Section 6 discusses the implications of our model for the broader regulatory debate around compulsory licensing. Section 7 concludes. Throughout the paper, all proofs that are not immediate from the context are collected in Appendix 1.

\section{The Model}

We analyse a homogeneous-product industry in which firms produce under constant marginal costs. The model consists of three stages - innovation, fixed-fee licensing and production, described in detail below - and is solved by backward induction.

\subsection{Stage 1 - Innovation}

Consider an innovation race defined in terms of the gap between a given firm's marginal cost and a baseline industry technology level. Suppose there are just two firms: the follower has the technology that defines the existing industry baseline, while the leader has a technology that is ahead of this industry baseline as a result of some previous innovation, to be understood in the sense of lower cost. We write these gaps in the initial position as $g_{F}=0$ and $g_{L}=G, 0<G<1$, for the follower and leader, respectively, where the maximum conceivable gap has been normalised to 1 . These gaps translate into marginal costs for firm $i$ of $c_{i}=1-g_{i}$, so that the initial marginal cost levels are $c_{F}=1$ and $c_{L}=1-G$ for the follower and leader, respectively. Firms invest in R\&D in order to be the first to discover a new technology that, for whoever is the first to discover, will increase their gap over the baseline industry technology by the amount $g, 0<g<1-G .^{16}$

We adopt the approach taken elsewhere in the innovation literature by approximating a firm's choice of hazard rate (that is, its instantaneous innovation probability, conditional on no firm having innovated up to that point) by its competitive threat. ${ }^{17}$ Let the hazard rate chosen by the leader be denoted by $x \geq 0$

\footnotetext{
${ }^{14}$ This terminology follows Beath et al. (1987, 1995). (The persistent dominance scenario has alternatively been described as one of "increasing dominance" in the literature. See, e.g., Vickers 1986.) See also Carlton and Gertner (2002), who argue that most R\&D-intensive industries, such as the IT, pharmaceutical and chemical industries, are characterised by action-reaction competition.

${ }^{15}$ Another concern in the action-reaction setting is that dominant firms may refuse to license in an attempt to limit the innovative advantage that less efficient firms enjoy.

${ }^{16}$ Our set-up is also consistent with certain representations of product quality. For example, in Häckner (2000) (assuming homogeneous products), demand for firm $i$ takes the form $p_{i}(Q)=\alpha_{i}-Q$, where $Q$ is total output and $\alpha_{i}$ is firm $i$ 's quality parameter. Since costs are normalised to zero in that framework, this is equivalent to our demand environment in which costs vary and quality remains constant (see Section 2.3 below).

${ }^{17}$ See, e.g., Ulph and Ulph $(1998,2001)$ and related literature (the term "competitive threat" is also used in Beath et al. 1989a, 1989b). The reliance on the competitive threat as the sole determinant of firms' innovation incentives may also be justified by the following scenario. Suppose that producing firms bid to acquire the innovation from an outside firm. In this auction game, if winning firms pay their own bids, the producing firms' bidding incentives will be given exactly by their competitive threats, since one firm will inevitably acquire the patent rights. In this setting,
} 
and that of the follower by $y \geq 0$. To gain closed-form solutions, we further assume that the R\&D costs are quadratic in hazard rates. In these circumstances, it is straightforward to show that the hazard rates chosen by the firms are ${ }^{18}$

$$
x=\frac{1}{2 r}\left(\pi_{L}^{w i n}-\pi_{L}^{\text {lose }}\right) \quad \text { and } \quad y=\frac{1}{2 r}\left(\pi_{F}^{\text {win }}-\pi_{F}^{\text {lose }}\right),
$$

where $r$ is the risk-free rate of interest, and $\pi_{i}^{\text {win }}$ and $\pi_{i}^{\text {lose }}$ denote the instantaneous operating profits that firm $i=L, F$ can earn in the product market, conditional on winning and losing the innovation race, respectively (the product market is described in detail in Section 2.3).

For many of our results, it will be sufficient to consider the rate-adjusted hazard rate, which we define as $X=2 r \cdot x$ for the leader and $Y=2 r \cdot y$ for the follower. Note that these are independent of the risk-free rate $r$. The preceding discussion therefore implies that the leader is the predicted winner of the innovation race if and only if $X>Y$.

\subsection{Stage 2 - Licensing}

For compulsory licensing to be a meaningful policy, it must be the case that not all firms decide to license their innovations voluntarily. Several papers have shown that precisely such an equilibrium involving full diffusion of innovations will result when licensing is based (in whole or in part) on per-unit royalties - in other words, royalty-based licensing is a sufficient condition for refusals to license not to occur. ${ }^{19}$ Hence, in order for the refusal to license problem to be meaningful, it is necessary to assume that licensing is based on fixed fees only. ${ }^{20}$

In our model, firms bargain over the licence fee at which the technology is shared, and this is assumed to result in a Pareto-efficient outcome. This implies that licensing will only occur voluntarily if it increases the firms' joint profits. We define compulsory licensing as a licensing deal that is (i) imposed by the competition authority when voluntary licensing is not feasible and (ii) priced below the incremental value that the innovation brings to the non-innovator (FRAND). This FRAND licence price is, moreover, assumed to be common knowledge. We will show in Section 6 as part of the regulatory implications of our model that this specification of the FRAND licence fee is also consistent with the wider FRAND literature.

\subsection{Stage 3 - Production}

We consider both a general demand environment, as well as a linear demand example where necessary for the results (see Section 2.4 below). At a general level, we suppose that product market competition takes the form of Cournot, with inverse demand given by the twice continuously differentiable function $P(Q)$, with $P^{\prime}(Q)<0$ whenever $P(Q)>0$, where $Q=q_{L}+q_{F}$ is aggregate output. Furthermore, we

the competitive threat represents an exact solution to the firms' R\&D investment problem. See, e.g., Reinganum (1983, p. 742).

${ }^{18}$ See Appendix 2 for a more detailed derivation of these results.

${ }^{19}$ See Kamien and Tauman (1986) and Kamien et al. (1992) for licensing based purely on royalties, and Sen and Tauman (2007) for the case of optimally combined fixed fees and royalties. Chen (2014) examines the particular case of a vertically integrated firm with a monopoly position in the upstream IP market that competes with a downstream rival. The key feature of the model is an exogenous probability of a follow-on innovation that makes the upstream IP market competitive. In that case, provided that the probability of follow-on innovation is sufficiently high, the integrated firm may refuse to license to the downstream rival, even with royalties, in order to exclude it and thereby maintain downstream dominance when the market for IP becomes competitive. We consider a more standard case with two vertically integrated firms that compete both in the IP and the product market, and with innovations that are, for the majority of the paper, non-drastic (non-essential). This allows us to focus more carefully on the implications of compulsory licensing for innovation (which we treat as a continuous rather than binary variable) and welfare.

${ }^{20}$ Rey and Salant (2012) is another example of a paper that assumes fixed fee licensing in the context of abuse of dominance regulation involving IP. 
assume that $P(0)>1$ and $P(Q)<1-(G+g)$ for $Q$ sufficiently high. Finally, we make the standard assumption that $P^{\prime}(Q)+Q P^{\prime \prime}(Q)<0$ for all $Q \geq 0$ with $P(Q)>0$ (Novshek 1985). These assumptions ensure the existence and uniqueness of a Cournot equilibrium, with intuitive comparative static properties. In particular, letting $\pi_{i}\left(g_{L}, g_{F}\right)$ denote the operating profits of firm $i=L, F$ as a function of the cost gaps, we have $\frac{\partial \pi_{i}}{\partial g_{i}}>0$ and $\frac{\partial \pi_{i}}{\partial g_{k}}<0, k \neq i$ (Amir et al. 2014; Linnemer 2003).

As is standard in homogeneous-product Cournot, equilibrium price, output and therefore consumer surplus depend only on the average cost (equivalently, the average cost gap). Consequently, in what follows, it is assumed that consumer surplus is a strictly increasing function of the combined cost gap, which we denote by $C S\left(g_{L}+g_{F}\right)$, with $C S^{\prime}>0$. Let

$$
\Sigma\left(g_{L}, g_{F}\right)=\pi_{L}\left(g_{L}, g_{F}\right)+\pi_{F}\left(g_{L}, g_{F}\right)
$$

denote industry profits associated with gaps $\left(g_{L}, g_{F}\right)$. Finally, let the sum of consumer surplus and firm profits (that is, total welfare) be denoted by ${ }^{21}$

$$
T W\left(g_{L}, g_{F}\right)=\Sigma\left(g_{L}, g_{F}\right)+C S\left(g_{L}+g_{F}\right) \text {. }
$$

Unless otherwise stated, we consider a non-drastic innovation, so that both firms produce positive output, both before and after innovation has occurred.

\subsection{Linear Demand Example}

Many of the results to be derived in this paper depend on the effect of discrete changes in the firms' marginal costs on industry profits. Whenever this rearrangement of costs is such that their sum (and therefore the average cost) remains constant, well-known results can be used to determine the profit effect for general demand functions. ${ }^{22}$ However, the majority of cost changes we consider do not satisfy this requirement: not only do costs change across firms, the average cost is also affected. In this case, there are no general results that determine the sign of the aggregate profit effect associated with discrete cost changes. ${ }^{23}$

We therefore introduce a simple linear-demand set-up to address this complication where it arises. Suppose then, for the sake of this example, that inverse demand is given by

$$
P(Q)=(1+\varepsilon)-Q, \quad \varepsilon>0
$$

The benefit of using this specification is that we can interpret the $\varepsilon$ parameter as a measure that is inversely related to the competitiveness of the market. This follows since, under the price-output combination $(P, Q)=(1, \varepsilon)$ (that is, the one which prevails if price equals marginal cost at the baseline technology level),

\footnotetext{
${ }^{21}$ This captures total welfare in an instantaneous, product market sense. An expression for present discounted total welfare, taking into account R\&D costs incurred at Stage 1 of the model and firms' innovation probabilities, will be derived in Section 4.2.

${ }^{22}$ Because, in that simple case, aggregate output, price, industry revenue and consumer surplus are unaffected. See Salant and Shaffer (1999).

${ }^{23}$ Février and Linnemer (2004) develop general results for marginal cost changes. Since we are concerned with discrete cost changes, these results apply here only in the sense of first-order approximations. While the nature of the results is unchanged under the approximation method, we focus on the linear demand set-up for tractability.
} 


$$
\varepsilon=-\frac{P^{\prime}(Q) Q}{P(Q)}
$$

Therefore $\varepsilon$ measures the inverse price elasticity of demand at the competitive equilibrium corresponding to the baseline industry technology level. ${ }^{24}$

In a Cournot equilibrium, industry profits are symmetric and are given by

$$
\Sigma\left(g_{L}, g_{F}\right)=\frac{1}{9}\left[\left(\varepsilon+2 g_{L}-g_{F}\right)^{2}+\left(\varepsilon+2 g_{F}-g_{L}\right)^{2}\right]
$$

while consumer surplus is equal to

$$
C S\left(g_{L}+g_{F}\right)=\frac{1}{18}\left(2 \varepsilon+g_{L}+g_{F}\right)^{2}
$$

In terms of notation, we write $z_{i}^{j s}$ for the value of variable $z$ that accrues to firm $i=L, F$ if the winner of the innovation race is firm $j=L, F$, and if the licensing regime is $s=N, V, C$, where $N$ denotes no licensing, $V$ denotes a voluntary licensing regime and $C$ denotes compulsory licensing. If a variable $z$ is written without subscript $i$, it accrues to society as a whole rather than to either of the firms.

\section{Innovation Effects of Compulsory Licensing}

Having outlined the individual components of our modelling framework, this section considers the innovation effects of compulsory licensing relative to a benchmark case in which firms are permitted to license voluntarily. As will be shown, compulsory licensing indeed imposes a cost by reducing aggregate $R \& D$ spending. Before deriving these results, it is useful to start by considering firms' innovation behaviour in the absence of licensing.

In our set-up, the predicted winner of the innovation race can be determined with reference to the rate-adjusted hazard rates, which depend solely on the difference in profits associated with winning and losing the innovation race. Noting that the cost gaps, conditional on the leader innovating, are $\left(g_{L}^{L N}, g_{F}^{L N}\right)=(G+g, 0)$, while, if the follower innovates, they are $\left(g_{L}^{F N}, g_{F}^{F N}\right)=(G, g)$, these rateadjusted hazard rates are given by

$$
X^{N}=\pi_{L}(G+g, 0)-\pi_{L}(G, g)
$$

and

$$
Y^{N}=\pi_{F}(G, g)-\pi_{F}(G+g, 0)
$$

for the leader and follower, respectively. So, if there is no licensing, the leader has a strictly greater incentive to innovate if and only if $X^{N}>Y^{N}$, which is to say

$$
\Sigma(G+g, 0)>\Sigma(G, g)
$$

\footnotetext{
${ }^{24}$ This measure of industry competitiveness is also used in Katsoulacos and Ulph (2013), for example. Measuring elasticity at the competitive equilibrium avoids the cellophane fallacy.
} 
As proved in Lemma 1 below, this condition is always satisfied, even in our general demand environment. It follows that we are in a persistent dominance setting.

Lemma 1 In the absence of licensing, the leader is the predicted winner of the innovation race, $X^{N}>Y^{N}$

Proof Appendix 1.

This lemma goes back to the increasing dominance result identified in Gilbert and Newberry (1982). As in that seminal paper, the industry evolves in the direction where industry profits are greater. In Gilbert and Newberry (1982), this is generally in the direction of continued monopoly - a phenomenon known as the efficiency effect. ${ }^{25}$ Even though we do not start from a monopoly position, it is straightforward to see that the joint profit comparison in (2) will always favour innovation by the leader in our Cournot setting, since average costs are unchanged while the variance of costs is greater if the leader innovates (Salant and Shaffer 1999). ${ }^{26}$

\subsection{Voluntary Licensing Benchmark}

Now consider the incentives of each firm to license its innovation voluntarily, conditional on innovating successfully. The consequence of either firm's decision to license its discovery is that both firms' cost gaps will increase by the amount $g$ following innovation. Therefore, if the leader wins and licenses, the cost gaps are equal to $\left(g_{L}^{L V}, g_{F}^{L V}\right)=(G+g, g)$. Conditional on the leader being the first to innovate, we can write the minimum price that the leader would be willing to accept for the licence and the maximum price that the follower would be willing to pay for the licence as

$$
\underline{P}^{L}=\pi_{L}(G+g, 0)-\pi_{L}(G+g, g)
$$

and

$$
\bar{P}^{L}=\pi_{F}(G+g, g)-\pi_{F}(G+g, 0)
$$

respectively. So, if the leader innovates, voluntary licensing will take place if and only if

$$
\Sigma(G+g, g)>\Sigma(G+g, 0) .
$$

As in the existing literature on fixed fee licensing (e.g. Katz and Shapiro 1985), voluntary licensing will occur if and only if such an agreement increases industry profits.

\footnotetext{
${ }^{25}$ See also Vickers (1986). Budd et al. (1993) show in the context of a more general dynamic model that the industry tends to evolve in the direction where firms' joint payoffs are higher. Harris and Vickers (1985) emphasise the role of asymmetrical patent races in the persistence of monopoly, while Reinganum (1985) explains the persistence of monopoly by a continuing process whereby successful entrants replace successive incumbents.

${ }^{26}$ Instead of relying on firms' competitive threats, we could alternatively rely on their profit incentives, defined as the difference between the profits from winning the innovation race and the status quo, to determine innovation incentives. This gives rise the replacement effect, which tends to favour innovation by the follower: since the incumbent earns more profits in the status quo, he faces (ceteris paribus) lower incentives to innovate. By focusing on the competitive threat (as has also been done in the existing literature, e.g. Ulph and Ulph 1998, 2001), we are implicitly emphasising the efficiency effect over the replacement effect. This simplification comes at no great cost, however, since our framework is still flexible enough to generate an action-reaction outcome, in which the follower is predicted to innovate successfully and overtake the incumbent (see Section 5). This will allow us to check the robustness of our main welfare results to a setting of action-reaction R\&D competition.
} 
If the follower wins the innovation race and licenses, the cost gaps are also equal to $\left(g_{L}^{F V}, g_{F}^{F V}\right)=(G+g, g)$. Therefore, provided licensing takes place, operating profits and consumer surplus are the same, regardless of which firm makes the innovation. The minimum price that the follower would be willing to accept for the licence and the maximum price that the leader would be willing to pay are, respectively,

$$
\underline{P}^{F}=\pi_{F}(G, g)-\pi_{F}(G+g, g)
$$

and

$$
\bar{P}^{F}=\pi_{L}(G+g, g)-\pi_{L}(G, g)
$$

Therefore, if the follower innovates, licensing will take place if and only if

$$
\Sigma(G+g, g)>\Sigma(G, g)
$$

Notice that, given that (2) holds, it follows from (5) and (8) that if the leader licenses the innovation, then the follower certainly will. Conversely, if the follower does not license the discovery, then neither will the leader. For competition authorities to want to compel firms to license, it must be the case that at least one of the firms would choose not to license voluntarily. So it certainly has to be the case that the leader - that is, the dominant firm - does not license. Consequently, in what follows, it will be assumed that $^{27}$

$$
\Sigma(G+g, g)<\Sigma(G+g, 0) .
$$

Since, if the follower licenses, both the average cost gap and the variance of costs increase, it is natural to assume that the follower will license, conditional on innovating. ${ }^{28}$ Hence it is assumed that (8) holds, which in combination with (9) implies that

$$
\Sigma(G+g, 0)>\Sigma(G+g, g)>\Sigma(G, g) .
$$

Let us denote the voluntary licence payment in case the follower discovers first and licenses by $P^{F}$, and write this as a weighted average of the reservation prices (6) and (7), so that

$$
P^{F}=\sigma\left[\pi_{F}(G, g)-\pi_{F}(G+g, g)\right]+(1-\sigma)\left[\pi_{L}(G+g, g)-\pi_{L}(G, g)\right]
$$

Here $\sigma, 0<\sigma<1$, is a parameter capturing the bargaining strength of the leader. Consequently, with voluntary licensing, the rate-adjusted hazard rates are given by

\footnotetext{
${ }^{27}$ In the context of our linear demand set-up, this condition is equivalent to the requirement that $2 \varepsilon<3 g+8 G$.

${ }^{28}$ See Salant and Shaffer (1999). In the context of our linear demand example, it is straightforward to verify that a sufficient condition for the follower to license is that $g<G$. This condition is far from being necessary, however. Indeed, the necessary and sufficient condition for the follower not to license is that $3 g>2 \varepsilon+10 G$. In other words, a necessary condition for the follower to refuse to license is that the gap opened up by the new discovery is more than three times as large as the initial gap of the leader.
} 


$$
\begin{aligned}
& X^{V}=X^{N}-\sigma[\Sigma(G+g, g)-\Sigma(G, g)], \\
& Y^{V}=Y^{N}+(1-\sigma)[\Sigma(G+g, g)-\Sigma(G, g)] .
\end{aligned}
$$

From (10) it follows that, if firms can license, this will reduce the hazard rate of the leader but raise the hazard rate of the follower. ${ }^{29}$ Nonetheless, the leader still remains the predicted winner of the innovation race, since, by (10),

$$
X^{V}-Y^{V}=\Sigma(G+g, 0)-\Sigma(G+g, g)>0 .
$$

In other words, the persistent dominance result in Lemma 1 is robust to the addition of voluntary licensing.

Before considering the innovation and welfare impacts of compulsory licensing, the following section discusses briefly the relevance of expectations and the "regulatory threat" for bargaining outcomes at the voluntary licensing stage. Importantly, the results presented in this section are robust to an alternative specification based on expectations.

\subsection{Voluntary Licensing and the "Regulatory Threat"}

So far, we have not taken explicit account of the fact that firms may anticipate a compulsory licence being imposed in case no voluntary agreement is reached. One may think that the mere threat of regulatory intervention could spur firms to agree voluntary deals that would not be agreed in the absence of such a threat. In that case, the threat of a compulsory licence being imposed might resolve the refusal to license problem in and of itself. This is closely related to the issue of voluntary agreements in environmental regulation, where the regulatory threat can have precisely this effect. ${ }^{30}$

However, if we let $\theta^{j}, 0 \leq \theta^{j} \leq 1$, denote the (common) probability with which firms anticipate a compulsory licence being imposed on innovating firm $j=L, F$ in case no voluntary agreement is reached, it is possible to show that the licensing conditions (5) and (8) are unchanged when we allow for arbitrary expectations. Intuitively, a higher probability of compulsory licensing distorts the firms' reservation prices towards the expected, exogenous FRAND fee. Since this just represents a transfer between firms that does not affect industry profits, the licensing conditions are still given by (5) and (8). Hence the threat of compulsory licensing alone cannot solve the underlying refusal to license problem (see Appendix 3 for further details).

\subsection{Compulsory Licensing}

Under a policy of compulsory licensing, the leader will be obliged by the competition authority to share its discovery at the FRAND price if it innovates successfully. Moreover, firms will take this into account when investing in R\&D. As discussed in Section 2.2, we assume that such a FRAND licence must be priced below the incremental value that the innovation brings to the non-innovator. This implies that the FRAND price must satisfy ${ }^{31}$

\footnotetext{
${ }^{29}$ This replicates the result of Katz and Shapiro (1985) and others, who show that voluntary licensing has an ambiguous effect on industry-wide innovation incentives, relative to no licensing. As in that paper, aggregate innovation incentives will rise if the bargaining strength of the licensor (here: the follower) is high, specifically if $1-\sigma>1 / 2$

${ }^{30}$ See, e.g., Manzini and Mariotti (2003), Arguedas (2005) and Segerson and Miceli (1998). A notable difference in the bargaining context analysed in those papers is that all firms lose out as a result of environmental regulation. In the compulsory licensing context, the non-innovator actually benefits when compulsory licensing is imposed.

${ }^{31}$ Note that the FRAND requirement is therefore equivalent to the requirement that $P^{F R A N D} \leq \bar{P}^{L}$ (see (4)). That is, the FRAND price must be below the willingness of the non-innovator to pay for the licence.
} 


$$
P^{F R A N D} \leq \pi_{F}(G+g, g)-\pi_{F}(G+g, 0)
$$

which we can write more conveniently as

$$
P^{F R A N D}=\phi\left[\pi_{F}(G+g, g)-\pi_{F}(G+g, 0)\right]
$$

where $\phi$ is a constant in the interval $[0,1]$. By simple algebraic comparison, it then follows that the hazard rates of the firms are always identical under compulsory licensing. Therefore the outcome of the innovation race becomes indeterminate.

Lemma 2 Under compulsory licensing, the hazard rates of the leader and follower are identical, $X^{C}=Y^{C}=P^{F R A N D}+P^{F}$.

The intuition for this result is clear. Regardless of whether a given firm wins or loses the innovation race, its operating profits will be constant because the innovation is shared in either case. Since what matters in determining the hazard rates is the difference in profits from winning and losing the innovation race, the incentives of the leader (to win so as to earn the FRAND fee and avoid paying under the voluntary licensing deal if the follower wins) are now exactly equal to those of the follower (to win so as to earn the voluntary licensing fee and avoid paying the FRAND price). Note also that this result is independent of the precise level at which the FRAND licence price is set.

The next result summarises the innovation incentives of firms across the voluntary and compulsory licensing regimes under persistent dominance. ${ }^{32}$

Lemma 3 The (rate-adjusted) hazard rates of the firms are ranked as follows, $X^{V}>Y^{V} \geq X^{C}=Y^{C}$.

Proof Appendix 1.

This result therefore confirms the cost side of the welfare trade-off discussed in the introduction: compulsory licensing reduces industry-wide innovation incentives.

\section{Welfare Effects of Compulsory Licensing}

This section develops the main welfare results of the paper, by balancing the negative impact of compulsory licensing on innovation incentives against its positive effect (in the form of increased industry output) on competition. Our analysis will consider in turn three welfare standards: consumer surplus, total welfare, and foreclosure.

\subsection{Consumer Surplus}

As a first step towards a full welfare analysis of compulsory licensing on the basis of a consumer surplus standard, we derive an expression for the expected present discounted value of consumer surplus, which accounts for R\&D effects. Let $v(x, y)$ denote this present discounted consumer surplus, given hazard rates $x$ and $y$. We know that consumer surplus before an innovation occurs is given by $C S(G)$, while consumer surplus following an innovation by firm $j=L, F$ and given licensing regime $s=V, C$ is denoted by $C S^{j s}$. We can then write the present discounted value of consumer surplus as ${ }^{33}$

\footnotetext{
${ }^{32}$ Since the focus of the paper is the effect of compulsory licensing relative to a voluntary licensing benchmark, we exclude for brevity the no-licensing regime from these comparisons.

${ }^{33}$ The derivation of this expression parallels the derivation of present discounted profits in Appendix 2.
} 


$$
v\left(x^{s}, y^{s}\right)=\frac{x^{s} \frac{C S^{L s}}{r}+y^{s} \frac{C S^{F}}{r}+C S(G)}{x^{s}+y^{s}+r} .
$$

The necessary and sufficient condition for consumer surplus to be higher under compulsory licensing than under voluntary licensing is

$$
v\left(x^{C}, y^{C}\right)>v\left(x^{V}, y^{V}\right)
$$

In order to isolate the effect of the risk-free interest rate $r$, we can write the above condition in terms of rate-adjusted hazard rates as

$$
\begin{gathered}
\frac{X^{C} X^{V}}{r^{2}}[C S(G+2 g)-C S(G+g)]+C S(G)\left(X^{V}+Y^{V}-2 X^{C}\right) \\
-X^{V} C S(G+g)-Y^{V} C S(G+2 g)+2 X^{C} C S(G+2 g)>0 .
\end{gathered}
$$

The first term in the above expression is positive and reflects the fact that, post-innovation, consumers will on average enjoy a higher level of surplus under compulsory licensing than under voluntary licensing, because the possibility that the leader will innovate and refuse to license is removed. The second term is positive because, as shown in Lemma 3, aggregate innovation rates are lower under compulsory licensing, which implies that consumers will enjoy the status quo surplus for longer in expectation. Hence the inequality can only fail on account of the terms on the second line, the sign of which is ambiguous. On the one hand, consumers will jump to a higher level of consumer surplus sooner under voluntary licensing since innovation rates are higher. On the other hand, the level of surplus that consumers will enjoy post-innovation under voluntary licensing is, on average, lower than that which they would enjoy under compulsory licensing, due to the technology transfer effect.

In what follows, and in keeping with our overall modelling framework which relates firms' innovation decisions to their competitive threats, we will simplify the problem by considering an economic environment in which the risk-free rate $r$ is 'low' ${ }^{34}$ Multiplying (15) through by $r^{2}$ and focusing on the limiting case where $r \rightarrow 0$ for ease of exposition, the consumer surplus effect is then positive if and only if

$$
C S(G+2 g)-C S(G+g)>0,
$$

which is clearly satisfied. Hence we have the following welfare result.

Proposition 1 When the risk-free rate is low, compulsory licensing increases consumer surplus, $v\left(x^{C}, y^{C}\right)>v\left(x^{V}, y^{V}\right)$.

Intuitively, when the risk-free rate is low, consumers are more concerned with the identity of the innovating firm and the associated licensing outcome than the precise timing of the innovation (this assumption is therefore most reasonable in high-tech industries, where the rate of innovation is relatively high). Moreover, since both firms' innovations result in a cost reduction of magnitude $g$ in this persistent dominance setting, consumers are also indifferent as to which firm actually innovates - only the decision of the innovating firm as to whether or not to license matters to consumers. Since compulsory licensing

\footnotetext{
${ }^{34}$ See (1), which shows that the competitive threats are weighted by the reciprocal of $r$. This assumption of low $r$ is, therefore, also implicit in the work of Ulph and Ulph $(1998,2001)$, for example, who similarly rely on the competitive threat as the principal determinant of firms' innovation decisions.
} 
obliges the leader to license its innovation, while under voluntary licensing it would have refused to do so, compulsory licensing is therefore unambiguously preferred to voluntary licensing in consumer surplus terms. It therefore follows that the presumption of legality that applies to refusals to license IP, as judged by a consumer surplus standard, is extremely weak in these circumstances.

A couple of remarks about this result are in order. Firstly, while the assumption of low $r$ clearly simplifies the problem significantly, there are nonetheless important dynamic effects at play in the model. In particular, if the magnitude of the firms' innovations differed, then the identity of the innovating firm matters to consumers and the consumer surplus effect of compulsory licensing could be negative, even when $r$ is low. This will happen whenever compulsory licensing distorts the innovation incentives, such that the relative likelihood of the less-significant innovation being made increases substantially. For this reason, it is important to check the robustness of our welfare results to a setting of action-reaction R\&D competition, in which firms do indeed differ in terms of the magnitude of their research discoveries. We show in Section 5 that our welfare results continue to hold in that setting.

Secondly, our assumption of low $r$ will in general be weaker than the limiting argument $r \rightarrow 0$, adopted in the derivation of (16), would imply. As $r$ is increased, the residual terms in (15) (i.e. those that are not discounter by $r^{2}$ ) play an increasingly important role. Nevertheless, when the residual terms are positive, Proposition 1 is reinforced, irrespective of the value of $r$. And, whenever they are negative, we can define a (strictly positive) critical value $\bar{r}$ on the basis of (15), such that the consumer surplus effect is positive whenever $r<\bar{r}$. While the sign of the residual terms is difficult to determine in general, we may observe that a higher FRAND licence fee, which moves $X^{C}$ closer to $X^{V}$ and $Y^{V}$, increases the likelihood that they are positive. ${ }^{35}$

\subsection{Total Welfare}

Using analogous notation to that in Section 4.1, we can write the present discounted total welfare resulting from hazard rates $x$ and $y$, given information sharing regime $s=V, C$, as

$$
W\left(x^{s}, y^{s}\right)=\frac{1}{x^{s}+y^{s}+r}\left\{\begin{array}{c}
x^{s}\left(\frac{T W^{L s}}{r}\right)+y^{s}\left(\frac{T W^{F}}{r}\right) \\
+T W(G, 0)-\left(x^{s}\right)^{2}-\left(y^{s}\right)^{2}
\end{array}\right\} .
$$

In terms of total welfare, compulsory licensing will be preferred to voluntary licensing if and only if

$$
W\left(x^{C}, y^{C}\right)>W\left(x^{V}, y^{V}\right)
$$

When the risk-free rate is low, the condition implied by (18) can be written as

$$
X^{C} X^{V} \Delta_{T W}+\Delta_{c}>0
$$

where

$$
\Delta_{T W}=T W(G+g, g)-T W(G+g, 0)
$$

35 This follows by inspection of the residual terms in (15), which may also be rewritten as $X^{V}[C S(G+2 g)-C S(G+g)]-\left(X^{V}+Y^{V}-2 X^{C}\right)[C S(G+2 g)-C S(G)]$. The more general problem with considering an environment in which $r$ is high is that, in that case, it is no longer true that the competitive threats dominate firms' innovation decisions. Instead, these will be based on their profit incentives (see footnote 26 above), moving this case outside the scope of the present framework. We therefore leave a full characterisation of the case where $r$ is high as the subject of future work. 
captures the difference in total welfare levels, absent $R \& D$ costs, and $\Delta_{c}>0$ is a term capturing the R\&D cost savings under compulsory licensing relative to voluntary licensing. The term $\Delta_{T W}$ may be further decomposed into a negative (see (10)) profit effect and a positive consumer surplus effect. Since, moreover, we can say on the basis of our linear demand example that $\Delta_{T W}$ is increasing in $\varepsilon$ (that is, the degree to which the market is uncompetitive) and positive whenever ${ }^{36}$

$$
8 \varepsilon>3 g+14 G
$$

we have the following result. ${ }^{37}$

Proposition 2 When the risk-free rate is low, the total welfare effect of compulsory licensing is positive whenever the underlying degree of competitiveness in the industry is sufficiently low.

While this result emerges algebraically from our linear demand example, we can relate it back intuitively to our interpretation of $\varepsilon$ as a measure of industry competitiveness (recall that $\varepsilon$ is a parameter that reflects the inverse price elasticity of demand, see Section 2.4). Thus the consumer gain from compulsory licensing is larger when the industry is less competitive due to a reduced dominance effect (consumers benefit when the leader's dominant position is reduced via compulsory licensing, and more so when the underlying market is inherently less competitive), while the reduction in total firm profits is smaller when the industry is less competitive due to an increased rivalry effect (the increase in rivalry implied by the compulsory licensing of the leader's innovation decreases joint profits, but less so when the underlying degree of market competitiveness is low than when the market is per se more competitive). Both factors will tend to make the total welfare effect positive when the underlying degree of competitive intensity in the industry is low.

If, on the other hand, the industry is sufficiently competitive, it is total welfare improving to allow the dominant firm to refuse to license, rather than imposing a compulsory licence.

\subsection{Foreclosure}

We now consider the final welfare standard that a competition authority may implement: a foreclosure standard. This is motivated by the concern that a refusal to license by the dominant firm may result in the follower exiting the market. Relaxing the assumption of a non-drastic innovation for this section, we can see that, in our linear demand example, foreclosure will occur whenever

$$
g_{L}>\hat{g}\left(g_{F}\right) \equiv \varepsilon+2 g_{F} .
$$

It follows immediately that forcing the leader to share its innovation guarantees that its lead over the follower will not exceed the critical level $\hat{g}\left(g_{F}\right)$ defined in (21).

This result holds far more generally, however. In homogeneous-product Cournot with constant marginal costs, each firm's output necessarily increases in response to a cost shock that reduces all firms' costs symmetrically (see, e.g., Février and Linnemer 2004). For our purposes, we can restate this existing result as follows.

\footnotetext{
${ }^{36}$ This follows because $\Delta_{T W}=(g / 18)(8 \varepsilon-3 g-14 G)$.

${ }^{37}$ It is well known that tournament models provide incentives for socially excessive investment in R\&D (see, e.g., Beath et al. 1995). It should be noted in this regard that the nature of our total welfare result is robust to the inclusion of spillovers (by which innovation incentives can be made arbitrarily small) and, as such, it is not driven by this average over-investment issue. See Appendix 4 for details.
} 
Proposition 3 If both firms are active before innovation occurs, compulsory licensing guarantees that both firms remain active post-innovation.

Compulsory licensing is therefore an effective policy to protect competition per se.

Having established these welfare results in the benchmark persistent dominance setting, in which the leader was the predicted winner of the innovation race, the remainder of the paper explores the robustness of these results to an alternative, action-reaction form of R\&D competition. In this case, it is the follower that is predicted to innovate successfully and thereby overtake the leader's technology. As will be shown, despite the fact that consumers are now no longer indifferent as to the identity of the innovating firm, our welfare results continue to hold under this alternative setting of R\&D competition.

\section{Action-Reaction R\&D Competition}

\subsection{Innovation Effects of Compulsory Licensing}

In order to generate action-reaction, we assume from now on that, if the follower innovates, its cost gap will increase by an amount $G+g$, while if the leader innovates, its gap will increase by $g$. This implies that both firms are now racing to achieve a post-innovation gap of $G+g$. In the absence of licensing, it is then straightforward to show that the rate-adjusted hazard rates of the firms can be written as

$$
\begin{aligned}
& X^{N}=\pi_{L}(G+g, 0)-\pi_{L}(G, G+g), \\
& Y^{N}=\pi_{F}(G, G+g)-\pi_{F}(G+g, 0) .
\end{aligned}
$$

It follows that the necessary and sufficient condition for the follower to be the predicted winner of the innovation race is

$$
\Sigma(G, G+g)>\Sigma(G+g, 0),
$$

which, in the context of our linear demand Cournot example, requires that

$$
2 \varepsilon>8 g+3 G .
$$

Thus action-reaction will occur in industries in which the baseline level of competitiveness is sufficiently low. Since we are interested in investigating the innovation and welfare effects of compulsory licensing in action-reaction industries, we assume that (22), and therefore (23), are satisfied.

\subsubsection{Voluntary Licensing Benchmark}

Turning to the firms' voluntary licensing decisions, note that the cost gaps, conditional on the leader innovating and licensing, are $\left(g_{L}^{L V}, g_{F}^{L V}\right)=(G+g, g)$. Hence the minimum price that the leader would accept in order to sell the licence and the maximum price that the follower would be willing to pay are still given by (3) and (4), which in turn implies that the leader will again license if and only if

$$
\Sigma(G+g, g)>\Sigma(G+g, 0) .
$$

If the follower innovates and licenses, then $\left(g_{L}^{F V}, g_{F}^{F V}\right)=(2 G+g, G+g)$. Hence the minimum price that the follower would accept for the licence, and the maximum price that the leader would be willing to pay are now 


$$
\underline{P}^{F}=\pi_{F}(G, G+g)-\pi_{F}(2 G+g, G+g)
$$

and

$$
\bar{P}^{F}=\pi_{L}(2 G+g, G+g)-\pi_{L}(G, G+g)
$$

respectively, and so licensing will take place if and only if

$$
\Sigma(2 G+g, G+g)>\Sigma(G, G+g)
$$

Now, on the basis of our linear demand example, (24) holds if and only if $2 \varepsilon>3 g+8 G$, while (27) holds if and only if $2 \varepsilon>3 g-7 G .^{38}$ So it will again be the case that if the leader chooses to license, the follower certainly will, while if the follower chooses not to license, then neither will the leader. Note, moreover, that condition (23) guarantees that the follower will license, conditional on innovating. We therefore assume that (27) is satisfied while (24) is not, and instead we have

$$
\Sigma(G+g, 0)>\Sigma(G+g, g)
$$

As in the persistent dominance case, this implies that only the follower will license its discovery voluntarily. The dominant firm, by contrast, will refuse to license.

Writing the voluntary licence payment in case the follower innovates as a weighted average of the reservation prices (25) and (26), this licence payment is equal to

$$
\begin{aligned}
P^{F}= & \sigma\left[\pi_{F}(G, G+g)-\pi_{F}(2 G+g, G+g)\right] \\
& +(1-\sigma)\left[\pi_{L}(2 G+g, G+g)-\pi_{L}(G, G+g)\right],
\end{aligned}
$$

where the parameter $\sigma, 0<\sigma<1$, again reflects the bargaining strength of the leader. The hazard rates under voluntary licensing then follow as

$$
\begin{aligned}
& X^{V}=X^{N}-\sigma[\Sigma(2 G+g, G+g)-\Sigma(G, G+g)], \\
& Y^{V}=Y^{N}+(1-\sigma)[\Sigma(2 G+g, G+g)-\Sigma(G, G+g)] .
\end{aligned}
$$

With reference to (27), we can see that, despite the follower having been more likely to innovate in the first place, introducing voluntary licensing increases the hazard rate of the follower and decreases the hazard rate of the leader. ${ }^{39}$

\subsubsection{Compulsory Licensing}

Following the same definition of FRAND licensing given in Section 2.2, the FRAND licence fee must again satisfy

\footnotetext{
${ }^{38}$ With reference to (23), in order for there to be a possibility that the leader will refuse to license in this actionreaction context, it must therefore be true that $g<G$.

${ }^{39}$ Of course, this also implies that the follower will remain the predicted winner of the race. By (22) and (27), we have $X^{V}-Y^{V}=\Sigma(G+g, 0)-\Sigma(2 G+g, G+g)<0$.
} 


$$
P^{F R A N D}=\phi\left[\pi_{F}(G+g, g)-\pi_{F}(G+g, 0)\right],
$$

with $0 \leq \phi \leq 1$. Unlike in the persistent dominance scenario, however, the operating profits of a given firm associated with winning and losing the innovation race are no longer equal under compulsory licensing, because the magnitude of the cost saving now depends on the identity of the innovating firm. As the next lemma shows, this in turn implies that, under action-reaction, the innovation incentives are not equalised when compulsory licensing is imposed.

Lemma 4 Under action-reaction, the follower remains the predicted winner of the innovation race when compulsory licensing is imposed, $Y^{C}>X^{C}$.

\section{Proof Appendix 1.}

Nonetheless, despite the fact that compulsory licensing does not equalise the hazard rates, since it reduces the hazard rate of the leader and (weakly) reduces the hazard rate of the follower, it will again reduce the industry-wide innovation incentives relative to the voluntary licensing benchmark. Therefore the cost of compulsory licensing in terms of reduced innovation rates remains, as summarised in the next result.

Lemma 5 Under action-reaction, compulsory licensing reduces aggregate $R \& D$ incentives relative to a voluntary licensing regime, $X^{V}+Y^{V}>X^{C}+Y^{C}$.

\section{Proof Appendix 1.}

Finally, denoting the absolute values of the changes in hazard rates by $\Delta X=X^{V}-X^{C}>0$ and $\Delta Y=Y^{V}-Y^{C} \geq 0$, it is also possible to show that $\Delta X>\Delta Y$ whenever $\Sigma(G+g, 0)>\Sigma(G+g, g)$, which, given (28), is satisfied. Hence we have the following result. ${ }^{40}$

Lemma 6 The imposition of compulsory licensing further strengthens the action-reaction properties of the innovation race, since $\Delta X>\Delta Y$.

We may now consider the welfare effects of compulsory licensing under action-reaction, as judged both by a consumer surplus standard and a total welfare standard. ${ }^{41}$

\subsection{Welfare Effects of Compulsory Licensing}

\subsubsection{Consumer Surplus}

In order to assess the consumer surplus implications of compulsory licensing, first consider the consumer surplus levels associated with the various outcomes of the innovation race. Let $C S^{F}=C S(3 G+2 g)$ denote the level of consumer surplus that results if the follower innovates under either voluntary or compulsory licensing, $C S^{L C}=C S(G+2 g)$ denote the level of surplus that results if the leader innovates under compulsory licensing, and $C S^{L V}=C S(G+g)$ denote the level of surplus that results if the leader

\footnotetext{
${ }^{40}$ In this sense, the refusal by the leader to license voluntarily can also be seen as an attempt to limit the extent of action-reaction in the market.

${ }^{41}$ The results from the foreclosure standard carry over unchanged to the action-reaction setting.
} 
innovates (and refuses to license) under voluntary licensing. Since $C S^{\prime}>0$, we know that $C S^{F}>C S^{L C}>C S^{L V}$.

Compulsory licensing will be consumer surplus preferred to voluntary licensing if and only if

$$
v\left(x^{C}, y^{C}\right)>v\left(x^{V}, y^{V}\right)
$$

With reference to (1) and (14), and assuming that the risk-free rate is low, this condition holds if and only if

$$
X^{C} X^{V}\left(C S^{L C}-C S^{L V}\right)+X^{V} Y^{C}\left(C S^{F}-C S^{L V}\right)-X^{C} Y^{V}\left(C S^{F}-C S^{L C}\right)>0 .
$$

Relative to the corresponding expression in the persistent dominance case (see (16)), the condition now includes a negative term. This reflects the fact that compulsory licensing no longer guarantees the most preferred consumer outcome because the identity of the innovating firm matters: there is a chance now that the leader will innovate under compulsory licensing, yielding $C S^{L C}$, while under voluntary licensing it would have been the follower that innovates, yielding $C S^{F}>C S^{L C}$ (this occurs with probability $x^{C} y^{V}$ ). Compared to the persistent dominance case, this makes compulsory licensing relatively less attractive when we have action-reaction.

Nonetheless, compulsory licensing must still be preferred to voluntary licensing in a probabilistic sense. This follows because compulsory licensing increases the relative likelihood that the follower will innovate, yielding the more valuable innovation to consumers (Lemma 6), while, if the leader were to innovate, the innovation will still be shared by compulsory licensing.

Formally, bearing in mind that $C S^{L C}>C S^{L V}$, a sufficient condition for (29) to hold is

$$
X^{V} Y^{C}>X^{C} Y^{V}
$$

which can be rewritten as

$$
1+\frac{\Delta X}{X^{C}}>1+\frac{\Delta Y}{Y^{C}}
$$

Since $\Delta X>\Delta Y$ (Lemma 6) and $X^{C}<Y^{C}$ (Lemma 4), this is always satisfied. Hence we have the following result.

Proposition 4 When the risk-free rate is low, compulsory licensing increases consumer surplus under action-reaction, $v\left(x^{C}, y^{C}\right)>v\left(x^{V}, y^{V}\right)$.

Thus, because compulsory licensing makes it relatively less likely that the leader will innovate, yielding the less significant innovation to society, our consumer surplus result in Proposition 1 has been shown to be robust to action-reaction R\&D competition.

\subsubsection{Total Welfare}

In this section, we let $\Sigma^{F}=\Sigma(2 G+g, G+g)$ denote industry profits if the follower innovates under either voluntary or compulsory licensing, $\Sigma^{L C}=\Sigma(G+g, g)$ denote industry profits if the leader innovates under compulsory licensing, and $\Sigma^{L V}=\Sigma(G+g, 0)$ denote profits if the leader innovates (and refuses to license) under voluntary licensing. We know from (22), (27) and (28) that $\Sigma^{F}>\Sigma^{L V}>\Sigma^{L C}$. 
Given the ranking of consumer surplus outcomes in Section 5.2.1, this also implies that $T W^{F}>\max \left[T W^{L C}, T W^{L V}\right]$.

The necessary and sufficient condition for compulsory licensing to be total welfare preferred to voluntary licensing is

$$
W\left(x^{C}, y^{C}\right)>W\left(x^{V}, y^{V}\right)
$$

where the $W$ function is given in (17). When the risk-free rate is low and excluding the cost savings term for simplicity, ${ }^{42}$ this condition can be written in terms of rate-adjusted hazard rates as

$$
\begin{gathered}
X^{C} X^{V}\left[T W^{L C}-T W^{L V}\right]+X^{V} Y^{C}\left[T W^{F}-T W^{L V}\right] \\
-X^{C} Y^{V}\left[T W^{F}-T W^{L C}\right]>0 .
\end{gathered}
$$

Therefore, if $T W^{L C}>T W^{L V}$, so that compulsory licensing would increase total welfare in a persistent dominance scenario, then this will also hold under action-reaction (since $X^{V} Y^{C}>X^{C} Y^{V}$, see (30)). If, on the other hand, $T W^{L V}$ exceeds $T W^{L C}$ to a sufficient degree, then the expression in (31) may turn negative. Given that, in the context of our linear demand example, the difference $T W^{L C}-T W^{L V}$ is increasing in $\varepsilon$ (that is, the degree to which the industry is uncompetitive, see (20)), this leads to our final welfare result, which replicates Proposition 2 in the action-reaction setting.

Proposition 5 When the risk-free rate is low, the total welfare effect of compulsory licensing is positive under action-reaction whenever the underlying degree of competitiveness in the industry is sufficiently low.

Moreover, given that (31) still holds when $T W^{L C}=T W^{L V}$, it follows that the threshold degree of "un-competitiveness" above which the total welfare effect turns positive is lower in the case of actionreaction than under persistent dominance. In that sense, the total welfare effect of compulsory licensing is actually more likely to be positive under action-reaction than under persistent dominance.

\section{Discussion and Regulatory Implications}

In this section, we discuss the implications of our model for the wider regulatory debate surrounding compulsory licensing. First, we consider in more detail the determination of FRAND licence fees and the implications of our model for optimal FRAND rates. We then discuss two further settings in which the issue of compulsory licensing has received widespread attention, namely in the context of SSOs and pharmaceutical trade.

While the fundamental trade-off between promoting consumer welfare and preserving innovation incentives is argued to be the same in these scenarios, they also contain specific features that go beyond the model we present in this paper. Nevertheless, we argue that these additional features actually make compulsory licensing a less controversial policy in welfare terms than it is in our setting. Therefore our results in favour of compulsory licensing (particularly under a consumer surplus standard) appear especially significant.

\footnotetext{
${ }^{42}$ This will of course tend to favour compulsory licensing over voluntary licensing in the total welfare comparison.
} 


\subsection{Price of Access and FRAND Licensing}

In this paper, we have adopted a very concise definition of FRAND licensing, which requires the FRAND licence fee to lie below the incremental value that the technology brings to the licensee (see Section 2.2). As this incremental value defines the non-innovator's willingness to pay for the innovation, see (4), such a licence price will unambiguously resolve the refusal to license problem. It is not surprising that this fundamental principle, namely that the FRAND fee must be below the licensee's willingness to pay in order to generate a licensing equilibrium, also underpins the current debate on FRAND licensing. Thus Carlton and Shampine (2013, p. 536) state that "[t]he maximum royalty [...] is based on the incremental value that the technology brings to the licensee compared with the alternatives available at that time" while, according to Mariniello (2011, p. 525), "the FRAND commitment waives the patent holder's right to refuse to license its IP rights to anybody seeking such a license." This requirement to license to all interested parties clearly implies that the FRAND price must lie below each licensee's willingness to pay. ${ }^{43}$ Beyond this intuitive basis for determining FRAND licence fees, there is currently no consensus on a precise method for calculating a FRAND licence price. ${ }^{44}$ It is important to emphasise, however, that our results are sufficiently general to cover any feasible FRAND price, since they hold for any licence fee below the non-innovator's willingness to pay.

Moving beyond this general principle, it is interesting to consider the implications of our model for welfare optimal FRAND licence fees. It is clear from Lemma 2 that both firms' innovation incentives are increasing in $P^{F R A N D}$ : the higher the FRAND price, the higher the cost to the follower from failing to win the innovation race, and the greater the reward to the leader from winning the race. Moreover, rewriting the hazard rates of the leader and follower under voluntary licensing (see (11)) as $X^{V}=\underline{P}^{L}+P^{F}$ and $Y^{V}=\bar{P}^{L}+P^{F}$, respectively, it is clear that aggregate innovation incentives will actually rise under compulsory licensing whenever

$$
P^{F R A N D}>\frac{1}{2}\left(\bar{P}^{L}+\underline{P}^{L}\right)
$$

Thus a sufficiently high FRAND rate appears to resolve the welfare trade-off implied by compulsory licensing in and of itself. However, since the refusal to license implies that $\underline{P}^{L}>\bar{P}^{L}$, any FRAND price satisfying (32) will exceed the follower's willingness to pay $\bar{P}^{L}$ and is therefore inconsistent with a licensing equilibrium. Instead we can conclude that, from a welfare point of view, the FRAND price should always be set at the maximum level (that is, exactly equal to the non-innovator's willingness to pay, $\phi=1$ in (13)) in order to mitigate the fall in innovation rates associated with compulsory licensing. ${ }^{45}$

\subsection{Compulsory Licensing in Standard-Setting Organisations}

A standard defines a set of technical or quality requirements with which a given product or production process must comply. Typically, such standards are agreed upon by SSOs, which may take the form of government agencies, quasi-legislative regulatory authorities or groups of industry participants. ${ }^{46}$ When a

\footnotetext{
${ }^{43}$ Implicitly, given that our model features only one licensee, we are focusing here on the "fair and reasonable" portion of the FRAND requirement. The extent to which innovators should be allowed to price discriminate between licensees under a FRAND regime is discussed in Swanson and Baumol (2005) and Mariniello (2011), for example. The incentives for owners of essential IP to charge excessive royalties and the associated impact on downstream competition is further discussed in Rey and Salant (2012) and Layne-Farrar and Schmidt (2010).

${ }^{44}$ See O'Donoghue and Padilla (2013, pp. 689-711) for a discussion of FRAND pricing in the context of recent cases.

${ }^{45}$ This argument implicitly assumes that aggregate innovation incentives were not socially excessive to begin with. Moreover, the claim made by the European Commission in Microsoft that compulsory licensing may actually increase innovation incentives (e.g. Komninos and Czapracka 2010) cannot hold in our framework. In other words, the trade-off between competition and innovation incentives is always real in our setting and our results in favour of compulsory licensing come about despite this trade-off.

${ }^{46}$ See O'Donoghue and Padilla (2013, p. 684) for more detail on the variety in types of SSOs. Two recent cases with relevance to the SSO context are Microsoft Corp. v. Motorola Inc. in the US, which established that Motorola had
} 
standard includes a technology that is covered by a given firm's patent, that patent is said to become "standard-essential". This designation as standard-essential bestows significant market power upon the patent-holding firm vis-à-vis its "locked-in" licensees, leading to a hold-up problem when patent-holders exploit this additional market power to exclude rivals or charge excessive licensing royalties for the use of the technology. To mitigate this hold-up problem, it is common for holders of standard-essential patents to commit ex ante to license their technology at FRAND rates once the standard is established. ${ }^{47}$ A simple revealed preference argument nevertheless shows that, despite this constraint on ex post licensing terms, the designation of a patent-holding firm's technology as standard-essential represents an important source of profits for that firm, which should, in itself, incentivise innovation: if inclusion in a standard were not profitable, firms would not go to such great lengths to have their IP deemed essential. ${ }^{48}$

The basic principle of FRAND licensing discussed in Section 6.1 does not change in this context: at a minimum, the FRAND price must still be such that it leads to a licensing equilibrium. ${ }^{49}$ Thus, by forcing innovators to license their technology below the minimum price they would have accepted voluntarily post-standard creation, the welfare impact of compulsory licensing again rests on the resolution of the trade-off between pro-competitive technology transfer and innovation incentives. Yet we may argue that, in the context of standards, the chilling effect of compulsory licensing on innovation incentives is likely to be less severe. This follows because compulsory licensing only affects standardessential technologies, a designation which should, in itself, promote innovation. Thus the principal difference between the SSO context and that described in this paper, the presence of a standard, should actually make the imposition of compulsory licensing less controversial in welfare terms. ${ }^{50}$

\subsection{Compulsory Licensing and Pharmaceutical Trade}

Compulsory licensing of pharmaceutical products by national governments is sanctioned under the 1994 World Trade Organization (WTO) agreement on Trade Related Aspects of Intellectual Property Rights (TRIPS) ${ }^{51}$ provided certain conditions are met. In particular, the justification for compulsory licensing in this context is not limited to antitrust but rather covers a broader concern for public welfare. Thus Article 31(b) of the TRIPS agreement states that the subject matter of a patent may be used without authorisation of the patent holder "in the case of a national emergency or other circumstances of extreme urgency or in cases of public non-commercial use." The Declaration adopted by the Fourth WTO Ministerial Conference in Doha, Qatar, in 2001 (the Doha Declaration ${ }^{52}$ ) went further in prioritising public health concerns over private IP rights by stating in Paragraph 5(b) that "[e]ach Member has the right to grant

violated its [F]RAND obligations with respect to its standard-essential patents, and Rambus in the EU, in which it was found that the firm had engaged in "patent ambush" by concealing its ownership of IP that was subsequently to be deemed essential as part of a new standard. Microsoft Corp. v. Motorola Inc., No. C10-1823JLR, 2013 WL 2111217 (WD Wash Apr 25, 2013); Rambus v. Commission, Case COMP/38.636 (2009).

${ }^{47}$ See, e.g., Sidak (2013, pp. 949-950) for relevant commitments in the policies of the European Telecommunications Standards Institute (ETSI) and the Institute of Electrical and Electronic Engineers (IEEE) SSOs.

${ }^{48}$ See, e.g., Chiao et al. (2007). Steady licensing revenue streams are one particular benefit of SSO membership.

${ }^{49}$ In fact, most of the contributions to the debate on FRAND licensing have to-date been set in the context of SSOs. One specific method of determining FRAND licence fees in the SSO setting is based on the Georgia-Pacific factors, a framework put forward by the US District Court for the Southern District of New York in Georgia-Pacific Corp. v. United States Plywood Corp. to determine appropriate damages in patent infringement cases. This damages calculation is itself based on an assessment of a "reasonable royalty", defined as the hypothetical voluntary licence price that would have been agreed between parties ex ante (see point 15 of the Georgia-Pacific factors). While this, at least conceptually, gets around the hold-up problem in SSOs, it is not helpful in the setting of our model absent standards, where an ex ante mutually agreeable voluntary licence price does not exist when the leader innovates. Georgia-Pacific Corp. v. United States Plywood Corp., 318 F.Supp. 1116, 1120 (SDNY 1970). See also Sidak (2013), Layne-Farrar et al. (2007) and literature cited therein for a discussion of FRAND licensing in the context of SSOs.

${ }^{50}$ It is worth noting that there may be other antitrust concerns that go along with the formation of standards, such as the potential for collusion among members of the standard, which we do not go into here. See, e.g., Schmalensee (2009). Furthermore, our framework does not cover non-vertically integrated firms and, since only one firm can innovate, it does not extend to competing technologies, which may raise further interesting questions in the SSO context.

${ }^{51}$ Available at: https://www.wto.org/english/tratop_e/trips_elt_agm0_e.htm.

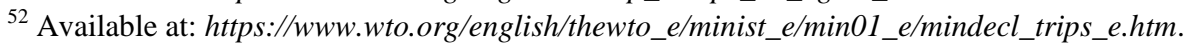


compulsory licences and the freedom to determine the grounds upon which such licences are granted" in order to protect public health and ensure access to medicines.

While the fundamental trade-off underlying compulsory licensing again revolves around innovation incentives and promoting public welfare, there is, therefore, a direct concern here with the prevention of health crises by guaranteeing access to essential medicines. Arguably, this threat of health emergencies should lead to greater weight being placed on the consumer surplus side of the welfare trade-off: "[ $t]$ he controversy that arises from the practice of placing compulsory licenses on pharmaceutical products becomes so complex because peoples' health and lives are on the line". 53 Thus, while the precise role played by this additional dimension of compulsory licensing in the pharmaceutical context - the fact that compulsory licensing is typically imposed in order to prevent health emergencies and save lives - is difficult to quantify, it nevertheless represents an additional factor, absent in our model, that strengthens the welfare case for compulsory licensing. ${ }^{54}$

\section{Conclusion}

This paper has developed a framework that clarifies the trade-off between competition and innovation incentives that competition authorities face when considering a compulsory licensing remedy. Our welfare results show that, despite the fact that innovation incentives fall when compulsory licensing is imposed, such a policy nonetheless increases consumer surplus when the risk-free rate is low. It follows that the presumption of legality surrounding refusals to license IP, assuming a consumer surplus standard, is not strong. This result therefore supports the approach taken by the European Commission in Microsoft, IMS Health and Magill, in which it ruled in favour of compulsory licensing on the basis of discriminating decision rules, rather than upholding the rights of IP holders by implementing a per se legality standard, as in the US Xerox case (Katsoulacos 2009). The imposition of compulsory licensing was also shown to be justified if the competition authority follows a foreclosure standard, since it guarantees that the dominant firm cannot foreclose its less-efficient rival.

The total welfare effect of compulsory licensing, meanwhile, depends on the underlying degree of competitiveness of the industry and is more likely to be positive when the industry in question is naturally less competitive. This result (abstracting from any conflicts with the stated consumer surplus goal of US competition policy) gives qualified support to the position adopted by the Federal Circuit in the landmark Xerox case, namely that refusals to license should be viewed as presumptively legal. Provided the underlying degree of competitiveness characterising the relevant industries is sufficiently high, allowing a dominant firm to refuse to license is superior to compulsory licensing in total welfare terms.

Finally, while the model presented in this paper is motivated by refusals to license IP in the absence of standards, we argued that it nevertheless serves as a useful benchmark for the study of compulsory licensing in the context of SSOs and pharmaceutical trade. As both the latter settings contain important additional features that strengthen the welfare argument for compulsory licensing, the case we explore in this paper can be seen as that in which the a priori arguments for compulsory licensing are weakest. This makes our results in favour of compulsory licensing, especially under a consumer surplus standard, particularly noteworthy.

\section{Appendix}

Appendix 1: Collected Proofs

Proof of Lemma 1. The sum of marginal costs (equivalently, cost gaps) is the same, regardless of which firm innovates. Therefore, on the basis of Salant and Shaffer (1999), since the variance of marginal costs

\footnotetext{
${ }^{53}$ Feldman (2009, p. 167). See also Khoury (2008), cited in Feldman (2009, p. 139), for a more extreme view: "patent protection should end where saving lives or alleviating suffering begins; that is, patent law should be subordinate to certain social interests".

${ }^{54}$ Of course, there are other specific factors relating to the pharmaceutical industry and trade-related aspects of compulsory licensing that also need to be taken into account. See, e.g., Stavropoulou and Valletti (2015) for further discussion of these points.
} 
is greater when the leader wins, we know that industry profits are also greater in that case: $\Sigma(G+g, 0)>\Sigma(G, g)$.

Proof of Lemma 3. Lemma 2 confirms the equality between hazard rates under compulsory licensing, while (12) confirms the rankings in the voluntary licensing regime. We can also see that compulsory licensing cannot lead to an increase in the hazard rate chosen by the follower, since, by (13),

$$
Y^{C}-Y^{V}=P^{F R A N D}-\pi_{F}(G+g, g)+\pi_{F}(G+g, 0) \leq 0 .
$$

The inequality is strict if we have $\phi<1$.

Proof of Lemma 4. We can write the rate-adjusted hazard rates under compulsory licensing as

$$
\begin{aligned}
& X^{C}=\pi_{L}(G+g, g)-\pi_{L}(2 G+g, G+g)+P^{F}+P^{F R A N D}, \\
& Y^{C}=\pi_{F}(2 G+g, G+g)-\pi_{F}(G+g, g)+P^{F}+P^{F R A N D} .
\end{aligned}
$$

The follower will remain the predicted winner of the race if and only if $Y^{C}>X^{C}$, which is to say

$$
\Sigma(2 G+g, G+g)>\Sigma(G+g, g)
$$

Given (22), (27) and (28), this is always satisfied.

Proof of Lemma 5. Compulsory licensing reduces the hazard rate of the leader and (weakly) reduces the hazard rate of the follower. By (28)

$$
X^{C}-X^{V} \leq \Sigma(G+g, g)-\Sigma(G+g, 0)<0 .
$$

Also,

$$
Y^{C}-Y^{V}=(1-\phi)\left[\pi_{F}(G+g, 0)-\pi_{F}(G+g, g)\right] \leq 0
$$

since $\phi \leq 1$.

Appendix 2: Firms' Innovation Behaviour in Tournament R\&D Model

This appendix presents a more formal derivation of firms' R\&D investment behaviour. It should be noted that our description of the single-stage, tournament model of R\&D competition follows standard treatments in the literature (e.g. Grossman and Shapiro 1987; Beath et al. 1989a, 1989b).

In this setting, firms decide at each instant of time, over the infinite horizon of the model, how much to invest in R\&D. Following the literature, it is assumed that a given firm's probability of innovating, conditional on no firm having innovated up to that point (that is, its hazard rate), depends solely on its current flow rate of $R \& D$ expenditure (there is no learning by doing). Therefore, if a given firm spends a constant amount on R\&D over time, its hazard rate will also be constant over time. Formally, this implies that if the leader, say, spends a constant flow amount on $\mathrm{R} \& \mathrm{D}$, the probability that it will discover by date $t$ is equal to $F(t ; x)=1-e^{-x t}$, yielding a hazard rate $H(t ; x)=[\partial F(t ; x) / \partial t] /[1-F(t ; x)]=x$, as required, and where $x$ is a constant that is determined by the amount that the leader invests in R\&D. 
(Similarly for the follower, $F(t ; y)=1-e^{-y t}$.) In particular, as noted in Section 2.1 , both firms are assumed to face the same innovation technology, which implies an R\&D cost that is quadratic in the chosen hazard rate (so the leader's flow cost of achieving hazard rate $x$ is $c(x)=x^{2}$, and likewise for the follower). Note finally that, since the decision problem faced by the firms is stationary, firms will indeed select a constant hazard rate over time.

In these circumstances, assuming that the firms can borrow and lend at the constant risk-free rate of interest $r$, the present discounted payoff to the leader from choosing hazard rate $x$ when the follower chooses hazard rate $y$, denoted by $V(x, y)$, is implicitly defined by ${ }^{55}$

$$
r V(x, y)=x\left[\frac{\pi_{L}^{w i n}}{r}-V(x, y)\right]+y\left[\frac{\pi_{L}^{\text {lose }}}{r}-V(x, y)\right]+\pi_{L}^{0}-x^{2}
$$

Here $\pi_{L}^{\text {win }}$ and $\pi_{L}^{\text {lose }}$ represent the flow profits earned by the leader in the product market, conditional on having won and lost the innovation race, respectively, and $\pi_{L}^{0}$ is the leader's status quo profit level. Equation (33) can be rearranged to yield

$$
V(x, y)=\frac{x\left(\frac{\pi_{L}^{w i n}}{r}\right)+y\left(\frac{\pi_{L}^{\text {lose }}}{r}\right)+\pi_{L}^{0}-x^{2}}{x+y+r}
$$

To derive the leader's reaction function, the first-order condition with respect to $x$ may be easily solved for. This shows that, as the follower's chosen hazard rate becomes arbitrarily large, $y \rightarrow \infty$ (so that the follower is almost certain to innovate), the leader's choice of hazard rate is determined by the competitive threat, defined as $\bar{x}=\frac{\pi_{L}^{\text {win }}-\pi_{L}^{\text {lose }}}{2 r}$. If, on the other hand, the follower is certain not to innovate, $y=0$, the leader selects its hazard rate on the basis of the profit incentive, defined as $x_{0}=\sqrt{\pi_{L}^{\text {win }}-\pi_{L}^{0}+r^{2}}-r$.

It is important to note that, when $r$ is low (consistent with our framework), the competitive threat is orders of magnitude larger than the profit incentive, and therefore dominates firms' R\&D investment decisions (in the sense that the firms' reaction functions intersect at a point that is well-approximated by their competitive threats. See, e.g., Beath et al. 1989a). This is the reason for which much of the applied literature has focused on the competitive threat as the key determinant of firms' innovation decisions (Ulph and Ulph 1998, 2001). As discussed in Section 2.1, in order to render the model solvable, we follow this approach by taking $x=\bar{x}$ for the leader and likewise for the follower (see (1)).

Appendix 3: Voluntary Licensing and the 'Regulatory Threat'

We wish to show that, when firms anticipate the possibility of a compulsory licensing remedy in case no voluntary agreement is reached, the licensing conditions (5) and (8) do not change. As described in Section 3.2 , let $\theta^{j}, 0 \leq \theta^{j} \leq 1$, be the common probability with which firms anticipate a compulsory licence being imposed on the innovating firm $j=L, F$ if a voluntary deal is refused. Moreover, let $P^{j(F R A N D)}$ now denote the FRAND licence price that applies in case firm $j=L, F$ innovates successfully and is forced to license by compulsory licence.

Then, in case the leader innovates and licenses, the cost gaps are $\left(g_{L}^{L V}, g_{F}^{L V}\right)=(G+g, g)$, while, if the leader innovates and does not license, the cost gaps would be $\left(g_{L}^{L N}, g_{F}^{L N}\right)=(G+g, 0)$ with

\footnotetext{
${ }^{55}$ In what follows, we will focus on the leader's decision problem with no loss in generality - equivalent expressions to those presented for the leader also hold for the follower.
} 
probability $\left(1-\theta^{L}\right)$, and $\left(g_{L}^{L N}, g_{F}^{L N}\right)=(G+g, g)$ with probability $\theta^{L}$. It follows that the minimum price that the leader would be willing to accept for the licence, and the maximum that the follower would be willing to pay, can be written as

$$
\underline{P}^{L}=\left(1-\theta^{L}\right)\left[\pi_{L}(G+g, 0)-\pi_{L}(G+g, g)\right]+\theta^{L} P^{L(F R A N D)}
$$

and

$$
\bar{P}^{L}=\left(1-\theta^{L}\right)\left[\pi_{F}(G+g, g)-\pi_{F}(G+g, 0)\right]+\theta^{L} P^{L(F R A N D)},
$$

respectively. That is, the reservation prices are now a weighted average of those that apply under voluntary licensing (see (3) and (4)) and the appropriate FRAND fee. Therefore, the leader will still license if and only if $\Sigma(G+g, g)>\Sigma(G+g, 0)$.

Similar derivations for the case when the follower innovates shows that the reservation prices in that case can be written as

$$
\underline{P}^{F}=\left(1-\theta^{F}\right)\left[\pi_{F}(G, g)-\pi_{F}(G+g, g)\right]+\theta^{F} P^{F(F R A N D)}
$$

and

$$
\bar{P}^{F}=\left(1-\theta^{F}\right)\left[\pi_{L}(G+g, g)-\pi_{L}(G, g)\right]+\theta^{F} P^{F(F R A N D)}
$$

Therefore, if the follower innovates, licensing will again take place if and only if $\Sigma(G+g, g)>\Sigma(G, g)$.

Since, in our general set-up of Section 2.3, it must hold that $\Sigma(G+g, 0)>\Sigma(G, g)$ (Salant and Shaffer 1999), the same intuition concerning the incentives of the leader to refuse to license carry over to this setting. Given (10), the leader has no (strict) incentive to license for all $0 \leq \theta^{L} \leq 1$. It follows that the threat of compulsory licensing alone cannot resolve the refusal to license problem.

Note that, when $\theta^{L}=1$, the leader's decision to license has no perceived effect on industry profits, because firms anticipate a compulsory licence with certainty in case no voluntary deal is reached. Therefore, the licensing conditions break down, and firms are indifferent between licensing and not licensing. We may assume that the leader still does not license in that case. Alternatively, note that $\theta^{L}=1$ implies that $\underline{P}^{L}=\bar{P}^{L}=P^{L(F R A N D)}$, so that the only voluntary deal that may be reached is the one which exactly replicates the compulsory licence. Therefore, from an analytical point of view, we can still talk of compulsory licensing with no loss in generality. ${ }^{56}$

\footnotetext{
56 This model therefore also nests the voluntary licensing regime of Section 3.1 (when $\theta^{L}=\theta^{F}=0$ ) and the compulsory licensing regime of Section 3.3 (when $\theta^{L}=1$ and $\theta^{F}=0$ ). Note that, in principle, it is also possible to allow $\theta^{F}$ to increase from zero under a compulsory licensing policy. This would shift the reservation prices, and therefore also the actual price at which the follower licenses towards $P^{F(F R A N D)}$. There are then two possibilities. To the extent that $P^{F(F R A N D)}$ is low, this would reduce the voluntary licence price $P^{F}$, and therefore reinforce the negative incentive effect that is already present in the model. To the extent that $P^{F(F R A N D)}$ is very high (that is, close to the incremental value $\pi_{L}(G+g, g)-\pi_{L}(G, g)$ ), however, an increase in $\theta^{F}$ could actually increase the voluntary licence fee $P^{F}$ and therefore provide an offsetting incentive effect relative to the voluntary licensing scenario. This possibility notwithstanding, since we typically think of compulsory licensing as a tool to combat the refusal by dominant firms to license, rather than one by which follower firms can extract higher prices for their licences, we stick with the model where $\theta^{F}$ remains constant at zero. This is, moreover, consistent with a setting in which compulsory licensing only affects dominant firms.
} 
We wish to demonstrate that our total welfare result is robust to the inclusion of spillovers, a standard method in the context of tournament models of R\&D to combat the excess investment problem. Suppose, to that end, that a fraction $s, 0<s<1$, of the technological progress engendered in any innovation spills over to the non-innovating firm. So, in the absence of licensing, if the leader innovates, the cost gaps would be $\left(g_{L}^{L N}, g_{F}^{L N}\right)=(G+g, s g)$, while if the follower innovates they would be $\left(g_{L}^{F N}, g_{F}^{F N}\right)=(G+s g, g)$. Therefore, we will have persistent dominance if and only if

$$
\Sigma(G+g, s g)>\Sigma(G+s g, g)
$$

This always holds (Salant and Shaffer 1999), so that we still have persistent dominance in our baseline scenario.

Now, given the assumption of fixed fee licensing, it is straightforward to see that, if the leader innovates, licensing will take place if and only if

$$
\Sigma(G+g, g)>\Sigma(G+g, s g)
$$

while, if the follower licenses, we will have voluntary licensing if and only if

$$
\Sigma(G+g, g)>\Sigma(G+s g, g)
$$

Given (34), it is still true that, if any firm were to refuse to license, it would be the leader, as in Section 3.1 .

What we now require in order for total welfare to be higher under compulsory licensing rather than voluntary licensing when $r$ is low (abstracting from cost savings) is that

$$
T W(G+g, g)>T W(G+g, s g) .
$$

This is equivalent to the requirement that ${ }^{57}$

$$
8 \varepsilon>\frac{(11 s+3)(1+s)}{1-s} g+14 G
$$

Therefore, the total welfare effect is still positive when the industry is sufficiently un-competitive (that is, when $\varepsilon$ is sufficiently high) - thus, the nature of Proposition 2 does not change. Nonetheless, the precise threshold level of "un-competitiveness" above which the total welfare effect turns positive is clearly increasing in the magnitude of the spillover parameter $s$. This is consistent with the idea that R\&D investment is more likely to be excessive from society's point of view when $s$ is low.

Acknowledgements I would like to thank David Ulph, Yannis Katsoulacos, Marco Mariotti, Vincenzo Denicolò, Yassine Lefouili, as well as participants of the 2013 CRESSE, EARIE and German Economic Association conferences, and the St Andrews Workshop on Competition, Innovation and Competition Policy for helpful comments and discussion. Financial support from the UK Economic and Social Research Council (grant number ES/J500136/1) and the Royal Economic Society (grant number RESJFS2014) is gratefully acknowledged. Any errors and omissions are my own.

\footnotetext{
${ }^{57}$ Clearly, setting $s=0$ returns the corresponding expression from the no-spillovers case analysed in the main body of the paper, see (20).
} 


\section{References}

Acemoglu, D., \& Akcigit, U. (2012). Intellectual Property Rights Policy, Competition and Innovation. Journal of the European Economic Association, 10(1), 1-42.

Aghion, P., Bloom, N., Blundell, R., Griffith, R., \& Howitt, P. (2005). Competition and Innovation: An Inverted-U Relationship. Quarterly Journal of Economics, 120(2), 701-728.

Amir, R., Encaoua, D., \& Lefouili, Y. (2014). Optimal Licensing of Uncertain Patents in the Shadow of Litigation. Games and Economic Behavior, 88, 320-338.

Arguedas, C. (2005). Bargaining in Environmental Regulation Revisited. Journal of Environmental Economics and Management, 50(2), 422-433.

Beath, J., Katsoulacos, Y., \& Ulph, D. (1987). Sequential Product Innovation and Industry Evolution. Economic Journal, 97(Conference 1987), 32-43.

Beath, J., Katsoulacos, Y., \& Ulph, D. (1989a). The Game-theoretic Analysis of Innovation: A Survey. Bulletin of Economic Research, 41(3), 163-184.

Beath, J., Katsoulacos, Y., \& Ulph, D. (1989b). Strategic R \& D Policy. Economic Journal, 99(Conference 1989), 74-83.

Beath, J., Katsoulacos, Y., \& Ulph, D. (1995). Game-theoretic Models of Innovation. In P. Stoneman (Ed.), Handbook of the Economics of Innovations and Technological Change (pp. 132-181). Oxford: Basil Blackwell.

Bond, E., \& Saggi, K. (2012). Compulsory Licensing, Price Controls, and Access to Patented Foreign Products. Vanderbilt University Department of Economics Working Papers, No. 12-00006.

Budd, C., Harris, C., \& Vickers, J. (1993). A Model of the Evolution of Duopoly: Does the Asymmetry between Firms Tend to Increase or Decrease? Review of Economic Studies, 60(3), 543-573.

Carlton, D. W., \& Gertner, R. H. (2002). Intellectual Property, Antitrust and Strategic Behavior. NBER Working Paper, No. 8976.

Carlton, D. W., \& Shampine, A. L. (2013). An Economic Interpretation of FRAND. Journal of Competition Law and Economics, 9(3), 531-552.

Chen, Y. (2014). Refusals to Deal, Intellectual Property Rights, and Antitrust. Journal of Law, Economics, and Organization, 30(3), 533-577.

Chiao, B., Lerner, J., \& Tirole, J. (2007). The Rules of Standard-Setting Organizations: An Empirical Analysis. RAND Journal of Economics, 38(4), 905-930.

Coco, R. (2008). Antitrust Liability for Refusal to License Intellectual Property: A Comparative Analysis and the International Setting. Marquette Intellectual Property Law Review, 12(1), 1-47.

DOJ-FTC (2007). Antitrust Enforcement and Intellectual Property Rights: Promoting Innovation and Competition. Retrieved July 25, 2015 from www.usdoj.gov/atr/public/hearings/ip/222655.pdf

European Commission (2007). Commission Decision of 24 May 2004 Relating to a Proceeding Pursuant to Article 82 of the EC Treaty and Article 54 of the EEA Agreement Against Microsoft Corporation (Case COMP/C-3/37.792 - Microsoft), Official Journal of the European Union, L32, 23-28.

Feldman, J. (2009). Compulsory Licenses: The Dangers Behind the Current Practice. The Journal of International Business and Law, 8(1), 137-167.

Février, P., \& Linnemer, L. (2004). Idiosyncratic Shocks in an Asymmetric Cournot Oligopoly. International Journal of Industrial Organization, 22(6), 835-848.

Gilbert, R. J., \& Newberry, D. M. G. (1982). Preemptive Patenting and the Persistence of Monopoly. American Economic Review, 72(3), 514-526.

Gilbert, R. J., \& Shapiro, C. (1996). An Economic Analysis of Unilateral Refusals to License Intellectual Property. Proceedings of the National Academy of Sciences USA, 93(23), 12749-12755.

Grossman, G. M., \& Shapiro, C. (1987). Dynamic R and D Competition. Economic Journal, 97(386), 372-387.

Häckner, J. (2000). A Note on Price and Quantity Competition in Differentiated Oligopolies. Journal of Economic Theory, 93(2), 233-239.

Harris, C., \& Vickers, J. (1985). Patent Races and the Persistence of Monopoly. Journal of Industrial Economics, 33(4), 461-481.

Iskhakov, F., Rust, J., \& Schjerning, B. (2013). The Dynamics of Bertrand Price Competition with CostReducing Investments. Univ. of Copenhagen Dept. of Economics Discussion Paper, No. 13-05.

Kamien, M. I., \& Tauman, Y. (1986). Fees versus Royalties and the Private Value of a Patent. Quarterly Journal of Economics, 101(3), 471-491.

Kamien, M. I., Oren, S., \& Tauman, Y. (1992). Optimal Licensing of Cost-reducing Innovation. Journal of Mathematical Economics, 21(5), 483-508. 
Katsoulacos, Y. (2009). Optimal Legal Standards for Refusals to License IP: A Welfare-based Analysis. Journal of Competition Law and Economics, 5(2), 269-295.

Katsoulacos, Y., \& Ulph, D. (2009). On Optimal Legal Standards for Competition Policy: A General Welfare-Based Analysis. Journal of Industrial Economics, 57(3), 410-437.

Katsoulacos, Y., \& Ulph, D. (2013). Antitrust Penalties and the Implications of Empirical Evidence on Cartel Overcharges. Economic Journal, 123(572), F558-F581.

Katz, M. L., \& Shapiro, C. (1985). On the Licensing of Innovations. RAND Journal of Economics, 16(4), 504-520.

Komninos, A. P., \& Czapracka, K. A. (2010). IP Rights in the EU Microsoft Saga. In I. Kokkoris \& F. Etro (Eds.), Competition Law and the Enforcement of Article 102 (pp. 224-241). Oxford: University Press.

Kühn, K.-U., \& Van Reenen, J. (2008). Interoperability and Market Foreclosure In the European Microsoft Case. Centre for Economic Performance Special Paper, No. 20.

Layne Farrar, A., Padilla, J., \& Schmalensee, R. (2007). Pricing Patents for Licensing in Standard Setting Organizations: Making Sense of FRAND Commitments. Antitrust Law Journal, 74(3), 671-706.

Layne-Farrar, A., \& Schmidt, K. M. (2010). Licensing Complementary Patents: Patent Trolls, Market Structure, and Excessive Royalties. Berkeley Technology Law Journal, 25(2), 1121-1144.

Linnemer, L. (2003). Backward Integration by a Dominant Firm. Journal of Economics and Management Strategy, 12(2), 231-259.

Manzini, P., \& Mariotti, M. (2003). A Bargaining Model of Voluntary Environmental Agreements. Journal of Public Economics, 87(12), 2725-2736.

Mariniello, M. (2011). Fair, Reasonable and Non-Discriminatory (FRAND) Terms: A Challenge for Competition Authorities. Journal of Competition Law and Economics, 7(3), 523-541.

Novshek, W. (1985). On the Existence of Cournot Equilibrium. Review of Economic Studies, 52(1), 8598.

O’Donoghue, R., \& Padilla, J. (2013). The Law and Economics of Article 102 TFEU. Oxford: Hart Publishing.

Pate, R. H. (2003). Antitrust and Intellectual Property. Address at the American Intellectual Property Law Association, January 24, 2003.

Reinganum, J. F. (1983). Uncertain Innovation and the Persistence of Monopoly. American Economic Review, 73(4), 741-748.

Reinganum, J. F. (1985). Innovation and Industry Evolution. Quarterly Journal of Economics, 100(1), 8199.

Rey, P. \& Salant, D. (2012). Abuse of Dominance and Licensing of Intellectual Property. International Journal of Industrial Organization, 30(6), 518-527.

Salant, S. W., \& Shaffer, G. (1999). Unequal Treatment of Identical Agents in Cournot Equilibrium. American Economic Review, 89(3), 585-604.

Schmalensee, R. (2009). Standard-Setting, Innovation Specialists and Competition Policy. Journal of Industrial Economics, 57(3), 526-552.

Segal, I., \& Whinston, M. D. (2007). Antitrust in Innovative Industries. American Economic Review, 97(5), 1703-1730.

Segerson, K., \& Miceli, T. J. (1998). Voluntary Environmental Agreements: Good or Bad News for Environmental Protection? Journal of Environmental Economics and Management, 36(2), 109-130.

Sen, D., \& Tauman, Y. (2007). General Licensing Schemes for a Cost-Reducing Innovation. Games and Economic Behavior, 59(1), 163-186.

Sidak, J. G. (2013). The Meaning of FRAND, Part I: Royalties. Journal of Competition Law and Economics, 9(4), 931-1055.

Stavropoulou, C., \& Valletti, T. (2015). Compulsory Licensing and Access to Drugs. European Journal of Health Economics, 16(1), 83-94.

Swanson, D. G., \& Baumol, W. J. (2005). Reasonable and Nondiscriminatory (RAND) Royalties, Standards Selection, and Control of Market Power. Antitrust Law Journal, 73(1), 1-58.

Ulph, A., \& Ulph, D. (1998). Labour Markets, Bargaining and Innovation. European Economic Review, 43(35), 931-939.

Ulph, A., \& Ulph, D. (2001). Strategic Innovation with Complete and Incomplete Labour Market Contracts. Scandinavian Journal of Economics, 103(2), 265-282.

Vickers, J. (1986). The Evolution of Market Structure when There is a Sequence of Innovations. Journal of Industrial Economics, 35(1), 1-12.

Vickers, J. (2010). Competition Policy and Property Rights. Economic Journal, 120(544), 375-392. 